\title{
Evaluation Symptoms Indices in Laryngopharyngeal Reflux Disease
}

\author{
Mohammed Tahir Ali ${ }^{1}$, Mohammed Rifaat Ahmed ${ }^{2}$, Aly Saber ${ }^{3, *}$ \\ ${ }^{1}$ Department of Otolaryngology, Faculty of Medicine, Jizan University, Ministry of Higher Education, Jizan , KSA \\ ${ }^{2}$ Department of Otolaryngology, Faculty of medicine, Suez Canal University, Ismailia, Egypt \\ ${ }^{3}$ Port-Fouad general Hospital, Port-Fouad, Egypt \\ Email address: \\ M_rifaat@hotmail.com (M. R. Ahmed),dr.tahirali@gmail.com (M. T. Ali), alysaber54@gmail.com (A. Saber)
}

\section{To cite this article:}

Mohammed Rifaat Ahmed, Mohammed Tahir Ali, AlySaber. Evaluation Symptoms Indexes inLaryngopharyngeal Reflux Disease. Journal of Surgery.Special Issue: Abdominal Surgery: Toward the Best.Vol. 4, No.1-1, 2016, pp. 24-26. doi: 10.11648/j.js.s.2016040101.16

\begin{abstract}
Objectives: to determine the indexes of the symptoms among patients laryngopharyngeal reflux disease. Design: A descriptive study. Setting: Suez Canal University Hospital, Ismailia, Egypt. Patients: 178 patients with symptoms of LFRD such as:- heart burn, Hoarseness of voice, persistent cough, globus pharyngeus, throat clearing. Intervention: patients were evaluated by ambulatory 24 hours $\mathrm{pH}$ monitoring, symptom intensity evaluation using the visual analog scale (VAS) , symptoms Frequency evaluation and index calculated by multiplication of the intensity and frequency the each symptom. Results: Heartburn was the most intensive typical symptom in the LPRD patients as mean intensity was $7.31 \pm 1.02$ points, mean HBI was $8.34 \pm 0.96$ points followed by persistence cough mean intensity was $6.81 \pm 1.75$ points, mean PCI was 7.12 \pm 1.28 points. Conclusion: LPRD patients mean indexes of atypical symptoms much higher than expected with a characteristic laryngoscopic findings are found.
\end{abstract}

Keywords: Larynx, Pharynx, Reflux, Intensity, Frequency, Index

\section{Introduction}

Laryngopharyngeal reflux (LPRD) is defined as backing contents of the stomach up into esophagus reaching the larynx and pharynx with variety of symptoms from typical reflux manifestations having the classic burning sensation to atypical non-acidic reflux(silent reflux )leads to poor quality of life ${ }^{(1-2)}$ Many etiological factor are traced for developing laryngopharyngeal reflux (LPRD) such as obesity with high body mass index (BMI), age and smoking. ${ }^{(3)}$ The most common symptoms include: excessive throat clearing, hoarseness of voice, globus pharyngeus, persistent cough , excess throat mucus and swallowing difficulties including dysphagia or/and odynophagia. ${ }^{(4)}$

Diagnosis of LPRD is usually done by ambulatory 24 hours $\mathrm{pH}$-monitor,endoscopically proved erosive reflux esophagitis or laryngitis and sometimes based on analysis and monitoring of changes of specific symptoms in response to antireflux treatment (Omeprasol test) ${ }^{(5)}$ Various questionnaires and scales for the evaluation of the intensity of the symptoms filled in by the patient have been used in several studies ${ }^{(6)}$.
This study aimed to determine the indices of the symptoms among patients with laryngopharyngeal reflux disease.

\section{Materials and Methods}

A descriptive study was conducted in Suez Canal university hospital - Ismailia - Egypt from 2010 to May 2012 and the local ethics committee approved the study. A total of178 patients with symptoms of LPRD such as:- heart burn , hoarseness of voice, persistence of cough, globus pharyngeus, throat clearing were included in our study while we exclude patients with history of, smoking, alcohol intake, anti reflux medical treatment or hiatus hernia .

All patients were subjected to symptom intensity evaluation using the visual analog scale (VAS), ranging from the absence of the symptom (score0) to severe intensity ( score10), symptoms Frequency evaluation $(0=$ absence, $1=$ recurrent, 2 = permanent) and Index was calculated by multiplication of the intensity and frequency the each symptom, : heart burn index (HBI) ,hoarseness of voiceindex (HoI), persistence of cough (PCI)globus pharyngeus index (GPI) throat clearing index (TCI).Intensity of: heart burn index (HBI), globus pharyngeus index (GPI) 
throat clearing index (TCI)were evaluated according to the VAS scale from 0 to 10 points as frequency of these symptoms was evaluated only as "recurrent" (1 point). Therefore, the possible values of TCI, HBI and GPI ranged from 0 to 10 points.

The values of hoarseness of voice index (HoI)and persistence cough (PCI) ranged from 0 to 20 points in relation to recurrent ( 1 point) or permanent ( 2 points).

All patients were subjected to ENT examination, Barium swallows (to exclude any associated disorder such as hiatus hernia), Laryngoscopic examination to demonstrate the laryngeal physician signs such as:-Red, irritated arytenoids, Small laryngeal ulcers, Swelling of the vocal cords or Granulomas in the larynx. ${ }^{(7)}$

Ambulatory 24 hours $\mathrm{pH}$ monitor using a sensor $5 \mathrm{~cm}$ above the upper border of the manometric lower esophageal sphincter in order to accurately diagnose LPR with calculation of mean percentage of the time $(\mathrm{pH}<4)^{(8)}$

\subsection{Statistical Analysis}

Data collected were processed using SPSS version 21 (SPSS Inc., Chicago, IL, USA). Quantitative data were expressed as means \pm SD while qualitative data were expressed as numbers and percentages [\%].

\subsection{Ethical Considerations}

Written consent was obtained from all patients before the study procedure. The local ethics committee approved the study.

\section{Results}

A total of $178 \mathrm{LPRD}$ patients with mean mage was $41.6 \pm$ 5.7 years, 94 males and 80 females, were falsifying our inclusion criteria with positive ambulatory 24 hours $\mathrm{pH}$ monitor.

Heart burn was the main complain represented in 161 patients $(92.5 \%)$ followed by persistence cough in 96 patients $(55.2 \%)$, then globus pharyngeus in 67 patients(38.5\%), then throat clearing in 45 patients $(25.8 \%)$ while Hoarseness of voice in 16 patients $(9.1 \%)$. (Table 1$)$

Table (1). shows the LPRD symptoms.

\begin{tabular}{lll}
\hline LFRD symptom & $(\mathbf{n}=\mathbf{1 7 4})$ & $\mathbf{\%}$ \\
\hline heart burn & 161 & $92.5 \%$ \\
persistence cough & 96 & $55.2 \%$ \\
globuspharyngeus & 67 & $38.5 \%$ \\
throat clearing & 45 & $25.8 \%$ \\
Hoarseness of voice & 16 & $9.1 \%$ \\
\hline
\end{tabular}

Red, irritated arytenoids was the main laryngoscopic findings in 88 patients $(50.6 \%)$ followed by Swelling of the vocal cords in 21 patients $(12.1 \%)$, Small laryngeal ulcers in 9 patients $(5.6 \%)$ while Granulomas in the larynx was the lowest represented findings occurred in 2 patients (1.1\%) .(Table 2)
Table (2). shows the laryngoscopic findings.

\begin{tabular}{lll}
\hline Laryngoscopic findings & $(\mathbf{n}=\mathbf{1 7 4})$ & $\mathbf{\%}$ \\
\hline Red, irritated arytenoids & 88 & $50.6 \%$ \\
Small laryngeal ulcers & 21 & $12.1 \%$ \\
Swelling of the vocal cords & 9 & $5.6 \%$ \\
Granulomas in the larynx & 2 & $1.1 \%$ \\
\hline
\end{tabular}

Symptoms indices were calculated by multiplication of the intensity and frequency the each symptom, : Heartburn was the most frequent and more intensive typical symptom in the LPRD patients as mean intensity was $7.31 \pm 1.02$ points, mean HBI was $8.34 \pm 0.96$ points. Persistence of cough mean intensity was $6.81 \pm 1.75$ points, mean PCI was $7.12 \pm 1.28$ points.

Throat clearing mean intensity was $4.16 \pm 1.08$ points, mean TCI was $6.78 \pm 0.46$ points. Globus pharyngeus mean intensity was $3.28 \pm 0.97$ points, mean GPI was $4.11 \pm 0.14$ points. Hoarseness of voice mean intensity was $3.12 \pm 0.46$ points, mean HoI was $5.27 \pm 0.89$ points. (table 3 )

Table (3). Mean intensity and Indexes of the symptoms in both H Pylori groups.

\begin{tabular}{lll}
\hline LFRD symptom & Mean & \pm SD \\
\hline Heart burn & & \\
Intensity & 7.31 & 1.02 \\
HBI & 8.34 & 0.96 \\
hoarseness of voice & & \\
Intensity & 3.12 & 0.46 \\
HoI & 5.27 & 0.89 \\
persistence cough & & \\
Intensity & 6.81 & 1.75 \\
PCI & 7.12 & 1.28 \\
globuspharyngeus & & \\
Intensity & 3.28 & 0.97 \\
GPI & 4.11 & 0.14 \\
throat clearing & & \\
Intensity & 4.16 & 1.08 \\
TCI & 6.78 & 0.46 \\
\hline
\end{tabular}

$\mathrm{HBI}=$ heart burn index

$\mathrm{HoI}=-$ hoarseness index

$\mathrm{PCI}=$ Chronic unexplained cough

$\mathrm{TCI}=$ throat clearing index

$\mathrm{GPI}=$ globuspharyngeus index

\section{Discussion}

Variety of symptoms presentation for LPRD were documented as atypical reflux symptoms presented with globus sensation or throat-clearing voice change, sore throat, dysphagia and cough. ${ }^{(9)}$ Pinar et al 2003 mentioned in his study on LPRD the most common symptom as dysphagia was $(56 \%)$ followed by hoarseness in $(46 \%) .{ }^{(10)}$ While Yorulmaz et al 2003 found that unexplained hoarseness, throat clearing, chronic cough, laryngospasm, globus, throat pain were the predominant symptoms in the laryngopharyngeal reflux disease patients group. ${ }^{(11)}$

Rouve et al 2005 investigated 46 patients with LFRD and found Posterior laryngitis in 33 patients documented edoscopically as a red irritant arytenoids.${ }^{(12)}$ Many authors mentioned that the laryngopharyngeal reflux disease is 
known to contribute to posterior acid laryngitis, laryngeal contact ulceration, granuloma formation, laryngeal cancer, chronic hoarseness, pharyngitis, asthma, pneumonia, nocturnal choking, and dental diseases. ${ }^{(13)}$ Tauber et al 2002 investigated 30 patients with LPRD he found that Posterior laryngitis was present in 26 patients and in 19 of them was accompanied by erythema and edema of the interarytenoid region. ${ }^{(14)}$

The fact that LPRD symptoms are considered as the most prevalent complains in the population of the developed countries, there are few data about the prevalence of these symptoms among people who consider themselves as healthy and do not consult a doctor, however. There are fewer studies related to the analysis of the intensity and frequency of the symptoms. $^{(15)}$

Our findings confirmed that the prevalence of atypical symptoms among the LPRD were much higher than expected. These findings point out an importance of evaluation of atypical symptoms in the diagnostics of LPRD. Habermann et al found that index of hoarseness was two and half times higher to compare with the indexes of the typical and atypical LPRD symptoms and it was determined that idiopathic hoarseness as a single symptom increases the odds ratio for LPRD when characteristic laryngoscopic findings were found and LPRD was suspected. ${ }^{(16)}$

\section{Conclusion}

LPRD patients mean indexes of atypical symptoms much higher than expected with characteristic laryngoscopic findings are found.

\section{References}

[1] Wang XY, Ye JY, Han DM. [Clinical value of 24-hour $\mathrm{pH}$ monitoring in patients with laryngopharyngeal reflux disease].Zhonghua Er Bi Yan Hou Tou Jing Wai Ke Za Zhi. 2007 Nov;42(11):834-8.

[2] Campagnolo AM, Priston J, Thoen RH, Medeiros T, Assunção AR .Laryngopharyngeal reflux: diagnosis, treatment, and latest research.Int Arch Otorhinolaryngol. 2014 Apr;18(2):184-91.

[3] Ezerarslan H, Çoban M, Kuran S, Akmansu ŞH, Özgüler Z, Beriat GK, Erkan G, Değertekin B, Kocatürk S. The relationship between heterotopic gastric mucosa in the cervical esophagus and laryngopharyngeal reflux.Kulak Burun Bogaz Ihtis Derg. 2012 Jan-Feb;22(1):6-11
[4] Angotoeva IB, Muldasheva AA. [The enhancement of the efficacy of early diagnostics of laryngopharyngeal reflux].Vestn Otorinolaringol. 2015;80(1):60-2. [Article in Russian]

[5] Wang J, Li X, Li J. Application of 24-hour MII-pH monitoring in the diagnosis of laryngopharyngeal reflux diseaseLin Chung Er Bi Yan Hou Tou Jing Wai Ke Za Zhi. 2015 Jan;29(2):190-3. [Article in Chinese]

[6] Rothman M, Farup C, Stewart W, Helbers L. Symptoms associated with gastroesophageal reflux disease: development of a questionnaire for use in clinical trials. Dig Dis Sci 2001;46(7):1540-9.

[7] Asaoka D, Nagahara A, Matsumoto K, Hojo M, Watanabe S. Current perspectives on reflux laryngitis.Clin J Gastroenterol. 2014 Dec;7(6):471-5.

[8] Wan Y, Yan Y, Ma F, Wang L, Lu P, Maytag A, Jiang JJ. LPR: how different diagnostic tools shape the outcomes of treatment.J Voice. 2014 May;28(3):362-8.

[9] Tomita T, Yasuda T, Oka H, Terao S, Arai E, Oshima T, Fukui $\mathrm{H}$, Hori K, Watari J, Miwa H. Atypical symptoms and healthrelated quality of life of patients with asymptomatic reflux esophagitis.J Gastroenterol Hepatol. 2015 Mar;30Suppl 1:1924.

[10] Pinar E,Oncel IS ,Calli C ,Atalay M: laryngopharyngeal symptoms and findings] Kulak BurunBogazIhtisDerg2003 Apr;10(4):153-8.

[11] Yorulamz I, OzlugedikS ,KucuK B: Gastroesophageal reflux disease: symptoms versus $\mathrm{pH}$ monitoring results Otolaryngol Head Neck Surg 2003 Nov;129(5):582-6.

[12] Rouve P, Chakarski I, Doskov D, Dimov G,StaykovaE:.Laryngopharyngeal symptoms and gastroesophageal reflux disease. J Voice -2005 Sep;19(3):47680 .

[13] Issing WJ , Karkos PD, Perreas K, Folwaczny C, Reichel O: Dual-probe 24-hour ambulatory $\mathrm{pH}$ monitoring for diagnosis of laryngopharyngeal reflux J laryngol Otol. 2004 Nov;118(11):845-8.

[14] TauberS ,Gross M ,Issing WJ:. Association of laryngopharyngeal symptoms with gastroesophageal reflux disease,Laryngoscope $2002,879-86$.

[15] Pribuisiene R, Uloza V, Jonaitis L. Typical and atypical symptoms of laryngopharyngeal reflux disease, Medicina (Kaunas). 2002;38(7):699-705. [Article in Lithuanian]

[16] Habermann W, Eherer A, Lindbichler F, Raith J. Ex juvantibus approach for chronic posterior laryngitis: results of shortterm pantoprazole therapy. J LaryngolOtol 1999;113:734-9. 